\title{
DigITALCOMMONS
}

11-1-2003

\section{Statistical Pronouncements II}

JMASM Editors

Follow this and additional works at: http://digitalcommons.wayne.edu/jmasm

Part of the Applied Statistics Commons, Social and Behavioral Sciences Commons, and the Statistical Theory Commons

\section{Recommended Citation}

Editors, JMASM (2003) "Statistical Pronouncements II," Journal of Modern Applied Statistical Methods: Vol. 2 : Iss. 2 , Article 28. DOI: $10.22237 /$ jmasm/1067646480

Available at: http://digitalcommons.wayne.edu/jmasm/vol2/iss2/28 


\section{Statistical Pronouncements II}

"There are some who appear to pride themselves on their absence of knowledge of mathematics. I never understood why it should be a matter of pride” - Arthur L. Bowley, (1934, Discussion, The Journal of the Royal Statistical Society, 97, p. 607).

"Do we know more than was known to Todhunter?” - Arthur L. Bowley, (ibid, p. 609).

"To try and state mathematics without either chalk or with a minimum of chalk [is] perhaps a hopeless task" - L. Isserlis (ibid, p. 614).

"The advantage of excluding by severe mathematical requirements many quacks is bought too dear if it shuts out a single John Graunt” - Major Greenwood (1939, Journal of the Royal Statistical Society, 102, p. 552).

"Many important applications of statistics, while employing elementary statistical techniques, demand thorough knowledge and long experience in the applied field" - William G. Cochran (1945, Training at the professional level for statistical work in agriculture and biology, Journal of the American Statistical Association, 40, p. 163).

"Youth is the time to learn mathematics" - William G. Cochran (1946, Graduate training in statistics, American Mathematics Monthly, 53(4), p. 199).

"Statistics depends primarily on mathematics and mathematicians for its future development... Such mathematicians need not be regarded as lost or strayed from the fold" William G. Cochran (ibid, p. 199).

"The missing link is that we do not know which of the theoretical non-normal distributions that have been studied are typical of the error distributions that turn up in practice" - William G. Cochran (1947, Some consequences when the assumptions for the analysis of variance are not satisfied, Biometrics, 3(1), p. 25).
"No valid sampling error formula exists unless the selection of the sample [is] through the use of an objective method of randomization” - William G. Cochran (1947, Recent developments in sampling theory in the United States, Proceedings of the International Statistical Institute, 3(A), p. 41).

"The student should be warned that he cannot expect miracles to be wrought by the use of statistical tools” - Quinn McNemar (1949, Psychological statistics, Wiley, p. 3.)

"Much ingenuity is shown by investigators in concocting possible explanations of the discrepancies among the results of different workers” - William G. Cochran (1950, The present status of biometry, Bulletin of the International Statistical Institute, 32(2), p. 133).

"Any estimate made from a sample is subject to error" - William G. Cochran (1951, Modern methods in the sampling of human populations, American Journal of Public Health, 41(6), p. 647).

"The principle that governs modern sampling practice is the familiar economic maxim that one should get the most for one's money” - William G. Cochran (ibid, p. 648).

"Any theory is at best approximately true, but nevertheless, if we are going to reject a theory, we do so because it does not fit the data we have, not because it would not fit a much larger sample of data that we do not have” William G. Cochran (ibid, p. 336).

"Sampling is all too often taken far too lightly” - William G. Cochran, (1954, Principles of sampling, Journal of the American Statistical Association, 49, p. 13).

"[There are] unwarranted shotgun marriages between the quantitatively unsophisticated idea of sample as 'what you get by grabbing a handful' and the mathematically precise notion of a "simple random sample"” William G. Cochran, (ibid, p. 13). 
"The scientist tends to think of seeing a statistician when he has some problem... mostly when something had gone wrong with the experiment or survey... As a result, statisticians... see a sorry collection of the wrecks of research projects" - William G. Cochran, (1955, Research techniques in the study of human beings, Milbank Memorial Fund Quarterly, 33(2), p. 122).

"In statistical training centers, something is done to teach young statisticians how to get along with scientists” - William G. Cochran (ibid, p. 123).

"The statistician is a poor marriage risk, and may be suffering from marital strain” William G. Cochran (ibid, p. 124).

"The ability to do experiments is one of the most powerful weapons man has for making advances in his understanding of the world" William G. Cochran (1957, The philosophy underlying the design of experiments, Proceedings of the $1^{\text {st }}$ Conference on the Design of Experiments in Army Research, Development and Testing, $\mathrm{p} 1$ ).

"All mathematical methods are oversimplifications” - William G. Cochran (1961, The role of mathematics in the medical sciences, New England Journal of Medicine, 265, p. 176).

"Many of the standard results in theoretical statistics were obtained without encountering really difficult mathematics” William G. Cochran (ibid, p. 230).

"Electronic machines... can free us from overdependence on the assumption of normality and from confinement to approximate linear solutions to nonlinear problems" - William G. Cochran (ibid, p. 232-232.)

\footnotetext{
"Nonparametric theory is elegant" Jaroslav Hajek (1969. A course in nonparametric statistics, Holden-Day, preface.)
}

"As regard the rejection of observations [as outliers], I distrust any slick formal rule" David J. Finney (1970, Discussion, Statistics in endocrinology, MIT Press, p. 72).

"Time is perhaps the most mysterious thing in a mysterious universe." - Maurice Kendall (1976, Time-series, p. 1).

"The modern theory of statistics began with the realization that, although individuals might not behave deterministically, aggregates of individuals were themselves subjects to laws which could often be summarized in fairly simple mathematical terms" - Maurice Kendall (ibid, p. 4).

"Some data are not worth analyzing, even when we have the big guns of a mathematical arsenal ready for attack" attributed to William G. Cochran by Frederick Mosteller in the Forward to Contribution to Statistics: William G. Cochran, Wiley, 1982, p. vii).

"There were just two qualifications for membership [in the national statistics society] first you had to have $\$ 5$ [and] second you had to be willing to give it to the society" - attributed to William G. Cochran by Frederick Mosteller (ibid, p. xi).

"You usually can't follow papers at meetings" - Frederick Mosteller (Contribution to Statistics: William G. Cochran, 1982, p. xii).

"It has been said that more time has been spent generating and testing random numbers than using them” - C. A. Whitney (1984, Generating and testing pseudo-random numbers, BYTE, October, 9(11), p. 128).

"Someone told me that each equation I included in the book would halve the sales" Stephen Hawkins (1988, A brief history of time: From the big bang to black holes, Bantam, p. vi.). 